\title{
Natural Gas Hydrates- Vast Resource, Uncertain Future
}

\section{Introduction}

Gas hydrates are naturally occurring icelike solids in which water molecules trap gas molecules in a cagelike structure known as a clathrate. Although many gases form hydrates in nature, methane hydrate is by far the most common; methane is the most abundant natural gas. The volume of carbon contained in methane hydrates worldwide is estimated to be twice the amount contained in all fossil fuels on Earth, including coal.

Estimates of the global resources of natural gas hydrate range from 100,000 to almost 300,000,000 trillion cubic feet (TCF) - to put these quantities in context, estimates of the remaining global reserves and undiscovered resources of conventional natural gas total about 13,000 TCF. Interest in natural gas hydrates will increase as finite conventional natural gas deposits are depleted. As concern increases about the effect of carbon dioxide on global warming, methane from hydrates will become an important opportunity. Combustion of methane adds significantly less carbon dioxide to the atmosphere than combustion of either coal or oil.

Gas hydrates occur at many sites along continental margins and in the Arctic (fig. 1). Yet we know very little about their composition, their volume, or the best ways to exploit their resource potential. The U.S. Geological Survey (USGS) is investigating many aspects of gas hydrates to understand their origin, their occurrence, the factors that affect their stability, and the possibility of using this vast resource in the world energy mix.

\section{Gas Hydrate: Ice That Burns}

Gas hydrate looks very much like ordinary ice, but if you put a match to it, it burns with a soft orange flame like the pilot light on a gas stove (fig. 2). Methane hydrates have been found in the subsurface in permafrost regions, but most occur in oceanic sediments hundreds of meters below the sea floor where water depths are

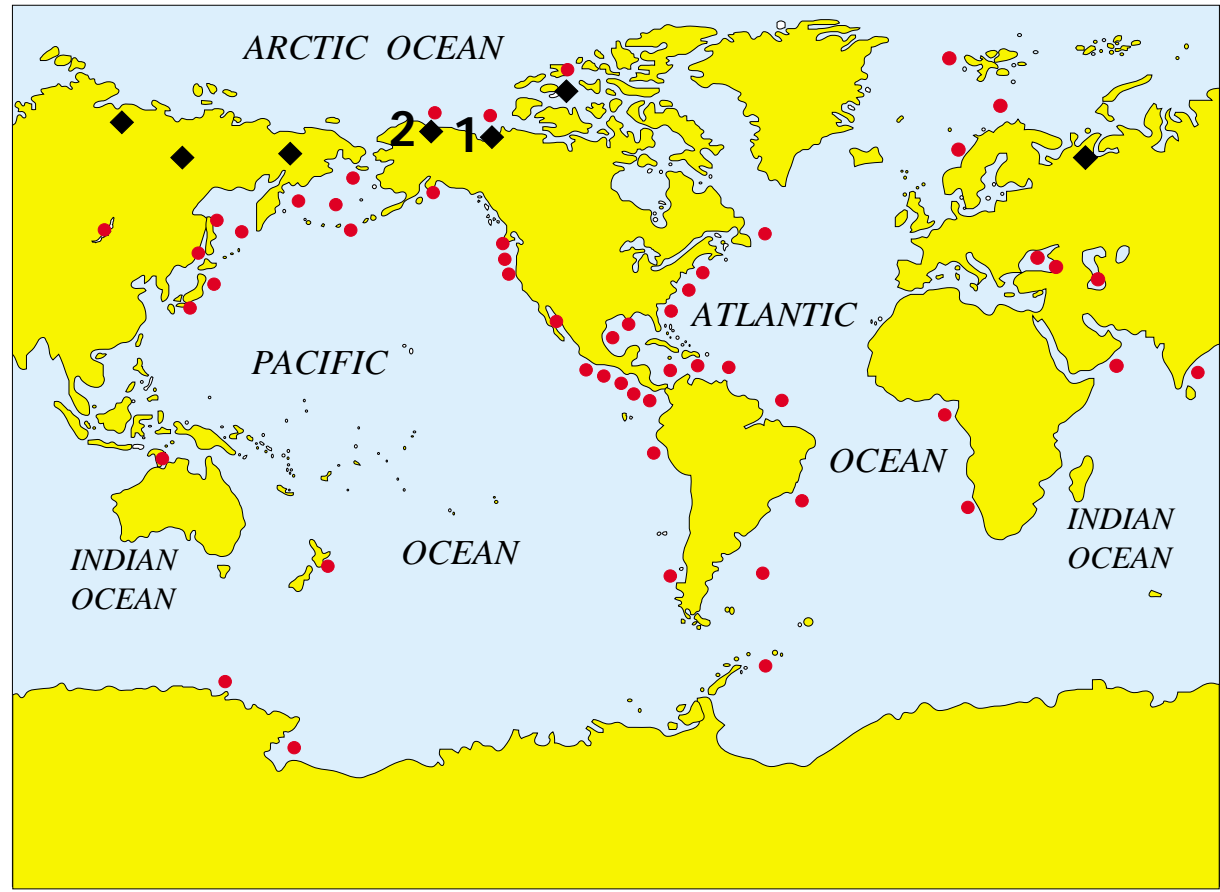

Figure 1. Known and inferred natural gas hydrate occurrences in marine (red circles) and permafrost (black diamonds) environments. Modified from K. A. Kvenvolden, U.S. Geological Survey (w ritten commun., 1999). The USGS is studying hydrates at sites 1 (Mackenzie Delta, Canada) and 2 (North Slope, Alaska).

greater than about 500 meters (fig. 1). Most occurrences of gas hydrate shown in figure 1 are inferred from geophysical logs in the permafrost regions and from anomalous seismic reflectors within ocean sedi-

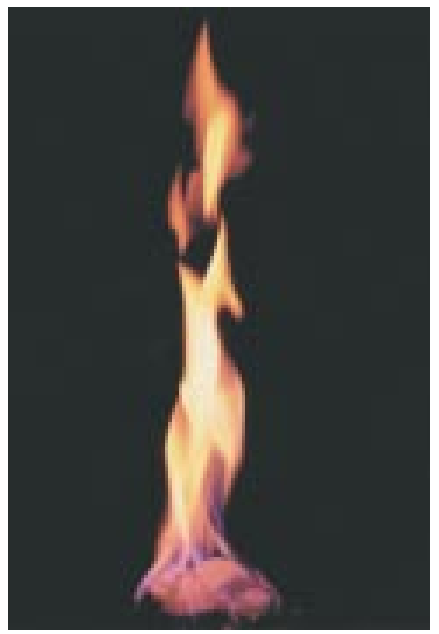

Figure 2. Burning synthetic (manmade) methane hydrates. Courtesy of the U.S. Department of Energy. ments called bottom-simulating reflectors, or BSR's, which are thought to indicate the base of the gas hydrate stability zone.

Examination of 90 gas hydrate samples recovered from 15 different geologic regions indicates that most samples consist of individual hydrate grains or particles in pores of sedimentary rocks. In general, the gas-hydrate-bearing zones in sedimentary sections range from tens of centimeters to tens of meters in thickness. Gas hydrate also occurs as nodules, laminae, and veins within sediment and, in one case, as a pure gas hydrate layer as much as 4 meters thick.

\section{Vast Quantities, B ut Are They Available?}

Natural gas hydrate resources appear to exceed the remaining recoverable conventional natural gas resources of the Nation and the world. USGS scientists estimate that the United States has in-place methane resources in methane hydrates of 
about 320,000 TCF (statistical mean estimate; see fig. 3); approximately half of this resource occurs offshore of Alaska, and most of the remainder is beneath the continental margins of the lower 48 States. Estimates of gas hydrate concentrations in individual accumulations show a considerable range, reflecting our lack of detailed knowledge. Although the concentration of methane hydrates in actual accumulations is still unclear, the possibility exists that large, economically extractable concentrations of energy exist in methane hydrate reservoirs.

USGS scientists have been conducting research on gas hydrates to answer questions like the following:

- In what form do gas hydrates occur in sediments?

- What is the quantity of gas actually available in individual gas hydrate accumulations?

- What production technology is required to develop this resource in a cost-effective manner?

While we don't have all the answers yet, we have made progress in understanding the challenges of recovering the gas from the hydrate. Proposed methods usually focus on dissociating or "melting" inplace gas hydrates by three methods:

- Heating the reservoir above hydrate stability temperatures by using hot water or steam injection

- Injecting an inhibitor, such as methanol or glycol, to decrease hydrate stability

- Decreasing reservoir pressure below hydrate equilibrium, thus allowing release of the methane gas contained in the clathrate

Although thermal stimulation is technically possible, the economic cost would be prohibitive. Similarly, flooding the hydrate accumulation with inhibitors appears to be technically feasible but impractical both economically and environmentally. The most economically promising method of producing gas from methane hydrates thus appears to be depressurization.

There are serious technical challenges to overcome. Most known marine gas hydrates are in fine-grained, clay-rich sediments with little or no permeability. Flow of gas to a well bore requires effective paths of fluid flow, but establishing such paths in low-permeability sediments may be exceedingly difficult. Where porous coarse-grained sediments occur on the continental margins within the zone of methane hydrate stability, such as in the Gulf of Mexico and off the eastern coast of India, fluid flow may be more easily established.

\section{Hazards}

Gas hydrates represent a hazard to conventional oil and gas production. In the Gulf of Mexico, oil and gas exploration is extending into water depths where gas hydrates occur at the sea floor. Pumping hot oil from great depths through drill pipes can cause warming of sediments and dissociation of hydrate, liberating large amounts of methane, weakening sediments, and perhaps generating pockets of highly pressured gas. The result might be gas blowouts, loss of support for pipelines, and sea-floor failure that could lead to underwater landslides and the release of methane from hydrates.

\section{Current USGS Research}

The USGS is investigating the resource potential of gas hydrates in two locations in the Arctic (fig. 1): the Mackenzie Delta of Canada and the North Slope of Alaska. In Canada, the USGS is working with an international consortium, led by the Geological Survey of Canada, to test technology to economically produce gas hydrates. In Alaska, the USGS, in partnership with the U.S. Department of Energy, is assessing the recoverability and potential production characteristics of onshore natural gas hydrate accumulations overlying the Prudhoe Bay and Kuparuk River oil fields. It is estimated that the known gas hydrate accumulations in northern Alaska may contain as much as $45 \mathrm{TCF}$ of natural gas.

\section{The Bottom Line}

The immense volume of methane hydrates worldwide may be a potential resource of extraordinary richness. Our understanding of these resources, however, is rudimentary-we do not yet know if these accumulations exist in sufficient concentration to make them economically viable, nor do we know enough about production technology to assume that even concentrated accumulations can be developed economically.

Use of natural gas will expand far into the 21 st century due to increasing demand for cleaner burning fuels and greater use in the transportation sector. It may well be

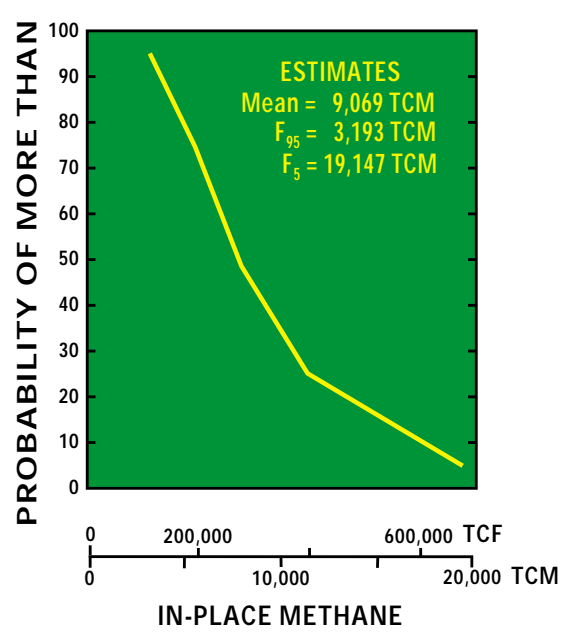

Figure 3. Cumulative probability curve show ing the estimated in-place methane resources within the methane hydrates of the United States. TCF, trillion cubic feet; TCM , trillion cubic meters. The curve is read as follows: there is a 95 percent chance $\left(F_{95}\right)$ that the methane hydrate resource potential is greater than 112,765 TCF $(3,193$ TCM $)$, and there is a 5 percent chance $\left(F_{5}\right)$ that the resource is greater than 676,110 TCF $(19,147$ TCM ). The mean estimate is 320,222 TCF $(9,069$ TCM ). Modified from figure 17 of T.S. Collett's article, Gas hydrate resources of the United States, in U.S. Geological Survey Digital Data Series DDS-30, release 2, 1996.

that government policy, responding, for example, to growing concern about climate change, will also influence the development of methane hydrates. In the past, government subsidies have driven development of other unconventional natural gas resources, including coal-bed methane. Now, as technology has developed, coalbed methane is a viable fuel in its own right, free of governmental incentives.

Despite all the apparent obstacles to the development of gas hydrate resources, it is good to remember that extraordinary technological developments in the petroleum industry - three-dimensional seismic techniques, secondary recovery methods, and horizontal drilling, for example-have led to the exploitation of resources once thought to be unavailable. Natural gas hydrates may also become economically extractable.

\section{For more information, please contact:}

Timothy Collett

U.S. Geological Survey

Denver Federal Center, MS 939

P.O. Box 25046

Denver, CO 80225

Telephone: 303-236-5731

E-mail: tcollett@usgs.gov 